\title{
ОПРЕДЕЛЕНИЕ ВИДА ХИМИЧЕСКИХ СВЯЗЕЙ В СУЛЬФАТАХ И ФТОРОСУЛЬФАТО- ЦИРКОНАТАХ НЕОДИМА МЕТОДОМ ИК СПЕКТРОСКОПИИ
}

Залкинд О.А., Годнева М.М.

Институт химии и технологии редких элементов и минерального сырья им. И.В. Тананаева КНЦ PAH, Anamumbl,zalkind@chemy.kolasc.net.ru

Недостаточная изученность индивидуальных свойств соединений неодима тормозит их применение на практике. Ранее система $\mathrm{TiO}_{2}-\mathrm{H}_{2} \mathrm{SO}_{4}-\mathrm{HF}-\mathrm{Nd}\left(\mathrm{NO}_{3}\right)_{3}-\mathrm{H}_{2} \mathrm{O}$ была изучена при содержании в растворах 6-7 мас.\% $\mathrm{TiO}_{2}$, м.о. $\mathrm{H}_{2} \mathrm{SO}_{4} / \mathrm{Ti}=3-8$ и Nd/Ti $=0.4-0.6$ при 50 и 75 ${ }^{\circ} \mathrm{C}[5,6]$. Выделены фазы $\mathrm{NdF}_{3}, \mathrm{Nd}_{2}\left(\mathrm{SO}_{4}\right)_{3} \cdot 8 \mathrm{H}_{2} \mathrm{O}, \mathrm{Nd}_{2}\left(\mathrm{SO}_{4}\right)_{3} \cdot 4 \mathrm{H}_{2} \mathrm{O}, \mathrm{NdTiOF}\left(\mathrm{SO}_{4}\right)_{2} \cdot 6 \mathrm{H}_{2} \mathrm{O}, \mathrm{Nd}_{4} \mathrm{Ti}_{3} \mathrm{~F}_{15}\left(\mathrm{SO}_{4}\right)_{4.5} \mathrm{nH} \mathrm{H}_{2} \mathrm{O}, \mathrm{NdFSO}_{4} \cdot \mathrm{nH}_{2} \mathrm{O}, \mathrm{NdF}_{3}$, $\mathrm{TiOSO}_{4} 2 \mathrm{H}_{2} \mathrm{O}, \mathrm{TiO}_{2} \mathrm{xH}_{2} \mathrm{O}$. Для них приведены ИК-спектры, которые записаны на старом оборудовании, и полосы поглощения в спектрах не разрешены, что не дало возможности должным образом их интерпретировать.

\section{Экспериментальная часть}

В качестве исходных компонентов использовали $\mathrm{TiOSO}_{4} 2 \mathrm{H}_{2} \mathrm{O}, \mathrm{Nd}\left(\mathrm{NO}_{3}\right)_{3} \cdot 6 \mathrm{H}_{2} \mathrm{O}$ (х.ч.), $\mathrm{H}_{2} \mathrm{SO}_{4}$ и $\mathrm{HF}$ марки «ос.ч.». Исследования проводили по разрезам системы $\mathrm{TiO}_{2}-\mathrm{H}_{2} \mathrm{SO}_{4}-\mathrm{HF}-\mathrm{Nd}\left(\mathrm{NO}_{3}\right)_{3}-\mathrm{H}_{2} \mathrm{O}$ при мольных отношениях (м.о.) $\mathrm{H}_{2} \mathrm{SO}_{4}: \mathrm{Ti}=2$ и $5, \mathrm{Nd}: \mathrm{Ti}=0.2$ и $0.5, \mathrm{~F}: \mathrm{Ti}=1-6$ и содержании в растворе 2-15 мас.\% $\mathrm{TiO}_{2}$. Концентрацию $\mathrm{TiO}_{2}$ рассчитывали с учетом разбавления водой, содержащейся в растворе фтористоводородной кислоты и гидрате неодима. Смеси выдерживали в течение 7-30 сут при $20^{\circ} \mathrm{C}$, затем образовавшиеся осадки отфильтровывали, промывали ледяной водой, спиртом с водой, спиртом. ИК-спектры записывали в области 300-3800 см-1 с помощью ИК Фурье спектрометра Nicolet 6700. Образцы готовили прессованием таблеток для записи в средней области с $\mathrm{KBr}$, для длинноволновой области - с CsJ. Спектры записаны для $\mathrm{NdF}_{3}$ (I), фазы $x$ (II), $\mathrm{NdTi}_{2} \mathrm{O}_{4 \cdot 75}\left(\mathrm{SO}_{4}\right)_{0.5} \cdot 3 \mathrm{H}_{2} \mathrm{O}(\mathrm{III}), \mathrm{NdTiOF}\left(\mathrm{SO}_{4}\right)_{2} \cdot 6 \mathrm{H}_{2} \mathrm{O}(\mathrm{IV}) \mathrm{Nd}_{2}\left(\mathrm{SO}_{4}\right)_{3} \cdot 8 \mathrm{H}_{2} \mathrm{O}(\mathrm{V}), \mathrm{Nd}_{2}\left(\mathrm{SO}_{4}\right)_{3} \cdot 4 \mathrm{H}_{2} \mathrm{O}(\mathrm{VI})$.

\section{Обсуждение результатов}

При м.о. F/Ti = 4-6 в осадках отмечены розового цвета, характерного для трехвалентного неодима, капсулы, состоящие из ядра и оболочки. Рентгенограммы оболочки и ядра идентичны. В них отражены сильные линии $\mathrm{NdF}_{3}$ (фаза I) [5] и примесь аморфной фазы, содержащей по данным ИКспектроскопии сульфат ион. Структура фазы I решена [4]. Во фториде неодима имеются только мостиковые атомы фтора. В ИК-спектре осадков с $\mathrm{NdF}_{3}$ отсутствует поглощение в области $450-550 \mathrm{~cm}^{-1}$, характерное для концевых атомов фтора. Имеется интенсивная полоса в области 376-381 cм ${ }^{-1}$, которой нет в спектрах сульфатов неодима. По-видимому, ее следует отнести к мостиковым атомам фтора.

Для осадков с фазой I отмечено поглощение в области 550-3800 $\mathrm{cm}^{-1}$, характерное для линий $\mathrm{SO}_{4}$-иона и $\mathrm{H}_{2} \mathrm{O}$, по которому выявлено наличие примеси фазы II (рис.), что подтверждено данными кристаллооптического анализа. Группа $\mathrm{SO}_{4}$, вероятно, бидентатна [2], а вода координирована к элементу-комплексообразователю (наличие поглощения $\rho$ ). В ИК-спектре ядра содержатся линии 841, 1400 и $1523 \mathrm{~cm}^{-1}$, которые относятся к анионам нитрата $\mathrm{Zr}\left(\mathrm{NO}_{3}\right)_{4} 5 \mathrm{H}_{2} \mathrm{O}$ [9], а также полосы, относящиеся к $\mathrm{SO}_{4}$-группам с волновыми числами, сходными с полосами для фазы II. Как следует из рентгенограммы [10] ядро состоит, в основном, из фаз I и II, но связи фтора с элементомкомплексообразователем не обнаружены.

Оболочка содержит $\mathrm{SO}_{4}$-группу с низкой симметрией $\mathrm{C}_{2 \mathrm{v}}$ или $\mathbf{C}_{\mathrm{sv}}$. Полагаем, что первоначально из исходного раствора осаждаются нитрат циркония и фторид неодима, образующие ядро. Затем, когда в растворе содержание нитрат-иона уменьшается, осаждается $\mathrm{NdF}_{3}$ с примесью аморфной фазы II, создавая оболочку.

Аморфная фаза II, отмеченная в сочетании с фазой I, отдельно не выделена. Фаза II содержит, судя по ИК-спектру, $\mathrm{SO}_{4}$-группу, количество которой уменьшается по мере увеличения м.о. F/Ti в исходной смеси и увеличивается с ростом содержания титана в исходном растворе. 


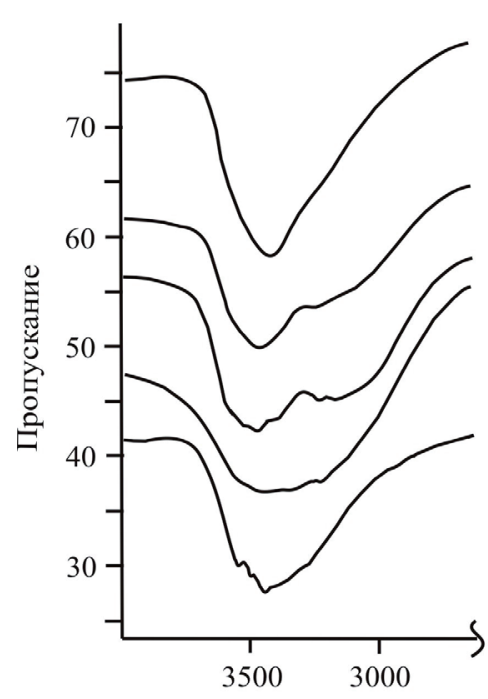

a

Волновое число (см-1)

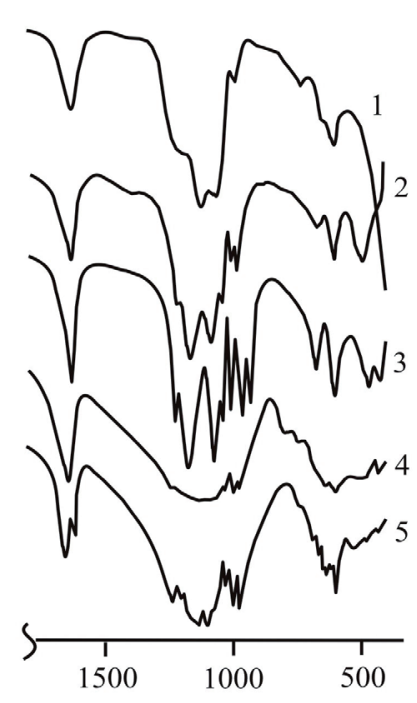

Рис. ИК-спектры.

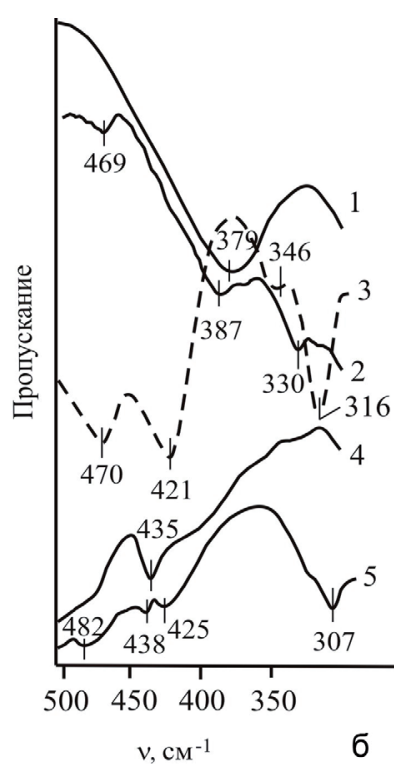

a - коротковолновая часть, б - длинноволновая; $1-\mathrm{NdF}_{3}$ и фаза х; $2,8-\mathrm{NdF}_{3}$ и $\mathrm{NdTi}_{2} \mathrm{O}_{4.75}\left(\mathrm{SO}_{4}\right)_{0.5} 3 \mathrm{H}_{2} \mathrm{O}$; $3,7-\mathrm{NdTiOF}\left(\mathrm{SO}_{4}\right)_{2} 6 \mathrm{H}_{2} \mathrm{O} ; 3-\mathrm{Nd}_{2}\left(\mathrm{SO}_{4}\right)_{3} 8 \mathrm{H}_{2} \mathrm{O} ; 5,6-\mathrm{Nd}_{2}\left(\mathrm{SO}_{4}\right)_{3} 4 \mathrm{H}_{2} \mathrm{O}, \mathrm{Nd}_{2}\left(\mathrm{SO}_{4}\right)_{3} 8 \mathrm{H}_{2} \mathrm{O}$ (мало).

Фаза III содержит два типа $\mathrm{SO}_{4}$-групп, судя по полосам $v_{1}$, причем возможно один тип с высокой симметрией до $\mathrm{T}_{\mathrm{d}}$, другой с более низкой - $\mathrm{C}_{3 \mathrm{v}}$. Судя по ИК-спектру фаза III, является иным сульфатом, чем фаза II. Ее состав, установленный методом термогравиметрии, $\mathrm{NdTi}_{2} \mathrm{O}_{4 \cdot 75}\left(\mathrm{SO}_{4}\right)_{0.5} \cdot 3 \mathrm{H}_{2} \mathrm{O}$ Она обнаружена по характерной линии на рентгенограмме при $14 \AA$. ИК-спектр осадка, содержащего фазы I и III, в длинноволновой области следует отнести к фазе III, т.к. фаза I не содержит $\mathrm{SO}_{4}$-групп.

Фаза IV в связи с отсутствием вращательных колебаний воды в спектре, содержит кристаллизационную воду. В ней имеется три типа $\mathrm{SO}_{4}$-групп (три полосы поглощения $v_{1}$ ), все высокой симметрии. $\mathrm{SO}_{4}$-группы мостиковые [2]. Атомы фтора связаны с титаном [5, 6]. Они концевые и мостиковые. Группы Ti-F и Ti-F-Ti, вероятно, связаны с неодимом через кислород $\mathrm{SO}_{4}$-групп.

Фаза $\mathbf{V}$ образует ярко розовые крупные кристаллы, структура которых решена методом РСтА $[1,3]$. Имеется два вида сульфатных групп: бидентатно мостиковая (связывает два атома неодима. Два других атома О с атомом неодима не связаны) и тридентатномостиковая (ее три атома кислорода входят по одному во внутренние сферы трех атомов неодима) [3]. По ИК-спектру в фазе имеется только одна полоса поглощения $v_{1} \mathrm{SO}_{4}$ с симметрией $\mathrm{C}_{3 \mathrm{v}}$ или $\mathrm{C}_{2 \mathrm{v}}$ и слабые полосы вращательных колебаний ( $\rho$ ) воды, присущие координированной воде. По-видимому, расстояния между кислородом $\mathrm{SO}_{4}$-групп и атомами неодима в бидентатно- и- тридентатно-мостиковых группах близки, и дентатность не отражается в ИК-спектре. Учитывая данные РСтА и ИК- спектроскопии для фазы V, определить дентатность $\mathrm{SO}_{4}$-групп нельзя. По данным ИК-спектроскопии фаза содержит два вида молекул воды (две полосы $\delta\left(\mathrm{H}_{2} \mathrm{O}\right)$.

По данным ИК-спектроскопии фаза VI, как и фаза V, содержит два вида молекул воды. Судя по набору полос, имеется также два вида $\mathrm{SO}_{4}$-групп: мостиковые и концевые, дентатность которых определить нельзя, исходя из данных для фазы V.

\section{Выводы}

ИК-спектры позволили установить наличие, число видов, симметрию $\mathrm{SO}_{4}$-групп в полученных ранее соединениях и уточнить дентатность тех же групп в отдельных фазах, даже до конца не идентифицированных, а также подтвердить наличие F-мостиков во фториде неодима. Установле- 
ны мостиковые $\mathrm{SO}_{4}$-группы в соединении $\mathrm{NdTiOF}\left(\mathrm{SO}_{4}\right)_{2} \cdot 6 \mathrm{H}_{2} \mathrm{O}$. Отмечено несоответствие числа видов $\mathrm{SO}_{4}$-групп в сульфате неодима, определенных методами РСтА и ИК-спектроскопии, чему дано объяснение. В составе ядра найден нитрат циркония, что позволило объяснить образование частиц типа ядро-оболочка.

\section{Литература}

1. Асланов Л.А., Рыбаков В.Б., Ионов В.М., Порай-Кошиц М.А., Иванов В.И. ДАН СССР. 1972. Т. 204, №5. C. 1122 .

2. $\quad$ Годнева М.М., Никитина С.Д., Мотов Д.Л. и др. // Журн. неорган. химии. 2001. Т. 46. № 5. С. 799.

3. Комиссарова Л.Н., Пушкина Г.Я., Шацкий В.М. и др. Соединения редкоземельных элементов. Сульфаты, селенаты, теллураты, хроматы. М.: Наука. 1986. 366 с.

4. Кондратюк И.П., Лошманов А.А., Мурадян Л.А. и др. // Кристаллография. 1988. Т. 33. С. 105.

5. Панасенко Е.Б., Белокосков В.И., Бегунова Р.Г. // Журн. неорган. химии. 1986. Т. 31. № 10. С. 2669.

6. Панасенко Е.Б., Загинайченко Н.И., Белокосков В.И. и др. // Журн. неорган. химии. 1988. Т. 33. № 12. C. 3171 .

7. Филатова С.А., Горощенко Я.Г., Янкович В.Н., Антишко А.Н. // Журн. неорган. химии. 1977. Т. 22 . № 4. C. 956.

8. Юрченко Э.П., Кустова Г.Н., Бацанов С.С. Колебательные спектры неорганических соединений. Новосибирск: Наука. 1981. 143 с.

9. Nyquist R.A., Kogal R.O. Infrared Spectra Inorganic Compounds. New-York-London: Academic Press. 1971. 500 pps.

10. The Powder Diffraction File. (International Centre for Diffraction Data). Cardes 23-1262, 83-2244, 73-195. 